\title{
GAMBARAN KARAKTERISTIK IBU, NILAI BISHOP DAN CARA TERMINASI PERSALINAN PADA PERSALINAN KALA 1 DENGAN INDUKSI PADA KETUBAN PECAH DINI DI RSUD K.R.M.T WONGSONEGORO, KOTA SEMARANG
}

\author{
Shinta Wurdiana Rhomadona, S.ST., M.Tr.Keb \\ STIKES William Booth Surabaya, Jln. Cimanuk No. 20, Telp. (031) 5633365 \\ Email : shintawurdiana24@gmail.com
}

\begin{abstract}
ABSTRAK
Pendahuluan : Persalinan dengan induksi merupakan salah satu intervensi obstetris yang paling sering diterapkan di seluruh dunia. Beberapa indikasi induksi persalinan yang paling sering adalah kehamilan post term, Ketuban Pecah Dini (KPD), kemungkinan terjadinya kegawatan, kondisi medis ibu yang dapat membahayakan kehamilan, sindrom antifosfolipid, korioamnionitis, solusio plasenta dan kematian janin. Manajemen persalinan pada KPD dengan induksi dapat mengurangi risiko morbiditas infeksi pada ibu tanpa meningkatkan persalinan dengan tindakan dan seksio cecaria, serta lebih sedikit bayi yang pergi ke perawatan intensif neonatal meskipun tidak ada perbedaan yang terlihat pada tingkat infeksi neonatal. Namun keputusan ini tetap dengan mempertimbangkan beberapa hal diantaranya presentasi janin, kematangan serviks, dan kemungkinan infeksi karena hal tersebut yang mempengaruhi keberhasilan induksi persalinan. Penelitian ini bertujuan untuk mengetahui karakteristik ibu, nilai shop dan cara terminasi persalinan pada persalinan kala 1 dengan induksi pada Ketuban Pecah Dini Di RSUD K.R.M.T Wongsonegoro, Kota Semarang. Metode : Desain penelitian yang digunakan adalah penelitian deskriptif. Jumlah jumlah sampel 30 orang. Pengambilan sampel dilakukan secara consecutive sampling. Hasil : Dari 30 ibu bersalin dengan induksi didapatkan rerata usianya adalah $30,66 \pm 5,88$ tahun dengan rentan usia responden termuda adalah 22 tahun dan usia tertua adalah 41 tahun. Paritas rerata responden adalah 2,03 $\pm 0,98$ kali dengan rentan jumlah kehamilan paling rendah 1 kali dan paling tinggi 4 kali. Rerata usia kehamilan adalah 40,01 $\pm 1,19$ minggu dengan rentan usia kehamilan termuda 37 minggu 2 hari dan usia kehamilan tertua adalah 41 minggu 5 hari. Sebagian besar ibu memiliki nilai bishop kurang dari 5 yaitu sebanyak 19 orang $(63,3 \%)$. Jenis persalinan pada penelitian ini mayoritas secara spontan yaitu sebesar $56,6 \%$.
\end{abstract}

Kata kunci : Karakteristik Ibu, Nilai Bishop, Cara Terminasi Persalinan, Induksi Persalinan, KPD 


\section{PENDAHULUAN}

Induksi persalinan merupakan salah satu intervensi obstetris yang paling sering diterapkan di seluruh dunia (Gommers JS, Diederen M, dkk, 2017). Data menunjukkan bahwa 1 dari 5 wanita hamil akan menjalani proses persalinan dengan induksi persalinan (Christina A. Penfield DAW, 2017) dan 30$40 \%$ wanita melahirkan akan dilakukan induksi persalinan ( Bomba-Opon D, dkk, 2017). Tujuan dari induksi persalinan adalah untuk merangsang kontraksi uterus dengan bantuan farmakologi medis atau tindakan medis sebelum onset persalinan normal (Christina A. Penfield DAW, 2017), walaupun induksi persalinan dianjurkan ketika resiko melanjutkan kehamilan lebih besar daripada proses persalinan namun sebaiknya perlu dipertimbangkan dengan pendekatan yang aman dan efisien, serta mempunyai manfaat lebih besar bagi kesehatan ibu dan bayi baru lahir (Christina A. Penfield DAW, 2017).

Beberapa indikasi induksi persalinan yang paling sering adalah kehamilan post term, Ketuban Pecah Dini (KPD), kemungkinan terjadinya kegawatan, kondisi medis ibu yang dapat membahayakan kehamilan, sindrom antifosfolipid, korioamnionitis, solusio plasenta dan kematian janin (Mozurkewich E CJ, 2009). Dalam panduan praktik 2007, American College of Ahli obstetri dan Ginekolog (ACOG) menyarankan induksi persalinan pada pasien yang didiagnosis KPD di kehamilan aterm ( Kui Li YW, dkk, 2011). Ketuban pecah dini (KPD) sering didefinisikan sebagai pecahnya selaput ketuban janin sebelum persalinan dimulai dengan insiden kejadian 8\% dari seluruh kehamilan (Gungorduk K, dkk, 2012). Salah satu pilihan manajemen persalinan Ketuban Pecah Dini pada keha milan cukup bulan adalah dengan induksi persalinan, dengan alasan sedapat mungkin memperpendek interval dari mulai pecahnya ketuban ke persalinan karena interval panjang dari pecahnya ketuban ke persalinan dikaitkan dengan peningkatan kejadian korioamnionitis, gawat janin dan sepsis neonatus. Hal ini dimungkinkan juga karena sudah hilangnya hambatan untuk menularkan infeksi dari vagina ke intrauterine Lorthe E, dkk, 2017).
Manajemen persalinan pada KPD dengan induksi dapat mengurangi risiko morbiditas infeksi pada ibu tanpa meningkatkan persalinan dengan tindakan dan seksio cecaria, serta lebih sedikit bayi yang pergi ke perawatan intensif neonatal meskipun tidak ada perbedaan yang terlihat pada tingkat infeksi neonatal. Namun keputusan ini tetap dengan mempertimbangkan beberapa hal diantaranya presentasi janin, kematangan serviks, dan kemungkinan infeksi karena hal tersebut yang mempengaruhi keberhasilan induksi persalinan. Namun demikian induksi dapat pula berakhir dengan kegagalan dan dikaitkan dengan kepuasan ibu yang kurang dan tingkat persalinan operatif meningkat secara positif dibandingkan dengan persalinan spontan dan perdarahan.

Berdasarkan latar belakang diatas maka peneliti tertarik untuk meneliti karakteristik ibu, nilai shop dan cara terminasi persalinan pada persalinan kala 1 dengan induksi pada Ketuban Pecah Dini Di RSUD K.R.M.T Wongsonegoro, Kota Semarang.

\section{METODE PENELITIAN}

Metode penelitian ini menggunakan metode deskriptif dengan pendekatan cross sectional yaitu suatu penelitian untuk mengetahui gambaran karakteristik ibu, nilai bishop dan cara persalinan pada ibu dengan induksi persalinan (Nursalam, 2007).

\section{Tempat dan Waktu Penelitian}

Penelitian ini dilakukan di RSUD K.R.M.T Wongsonegoro, Kota Semarang pada Bulan Maret - April 2019.

\section{Variabel penelitian dan defenisi operasional}

Definisi operasional adalah definisi berdasarkan karakteristik yang diamati (diukur). Pada penelitian ini menggunakan 3 variabel tunggal yaitu karakteristik ibu, nilai bishop dan cara persalinan.

\section{Populasi dan Sampel}

Populasi adalah wilayah luas yang terdiri dari objek dan subjek yang mempunyai karakteristik tertentu yang pilih oleh peneliti (Sugiyono, 2010). Populasi dalam penelitian ini adalah semua ibu bersalinan kala 1 dengan 
induksi pada Ketuban Pecah Dini di RSUD K.R.M.T Wongsonegoro, Kota Semarang selama bulan Maret - April 2019. Teknik sampel pada peneliti ini menggunakan consecutive sampling. Jumlah sampel yang dibutuhkan dalam penelitian ini adalah 30 yang memenuhi kriteria inklusi dan tidak termasuk kriteria eksklusi. Kriteria inklusi dan ekslusinya antara lain:

a. Kriteria Inklusi :

i. Ibu bersalin yang memasuki kala I dengan adanya dilatasi dan pendataran serviks dan kontraksi adekuat minimal 2 kali dalam 10 menit dengan durasi $>20$ detik,

ii. Ibu mendapatkan terapi induksi persalinan baik secara oral, infus atau pervaginam sesuai indikasasi medis,

iii. Ibu bersalin baik primipara atau multipara,

iv. Kehamilan tunggal

v. Kehamilan cukup bulan antara > 37 minggu sampai dengan < 42 minggu,

vi. Kondisi ketuban utuh ataupun sudah pecah,

vii. Kondisi jasmani dan rohani ibu sehat,

viii. Bersedia menjadi responden.

b. Kriteria Eksklusi :

i. Ibu memiliki kulit sensitif atau mudah alergi,

ii. Ibu memiliki luka dibagian perut,

iii. Waktu persalinan $>24$ jam atau terjadi persalinan lama

Pada penelitian ini peneliti menggunakan consecutive sampling yaitu teknik penetapan sampel dengan cara memilih sampel di antara populasi sesuai yang di kehendaki peneliti sampai jumlah sampel yang diperlukan terpenuhi. Jumlah sampel yang dibutuhkan dalam penelitian ini adalah 25 responden.

\section{Pengumpulan data}

Menurut Arikunto, (2007). Teknik pengumpulan data pada penelitian ini adalah mengunakan jasa data primer dan data sekunder. Data primer diperoleh secara langsung yaitu dengan membagikan kuesioner langsung pada responden, kemudian memberikan surat pernyataan persetujuan menjadi responden untuk ditandatangani setelah itu penelitian memberikan kuisioner.

\section{HASIL PENELITIAN}

Selama periode penelitian, dilakukan pengambilan data karakteristik responden yang memenuhi kriteria inklusi dan kriteria eksklusi. Karakteristik responden dalam penelitian ini terdiri dari usia ibu, paritas, usia kehamilan, nilai bishop dan jenis persalinan. Secara rinci data tentang karakteristik penelitian ini dapat dilihat pada tabel dibawah ini.

\section{Tabel 1. Karakteristik Ibu Kala 1 dengan persalinan induksi}

\begin{tabular}{lccc}
\hline \multicolumn{1}{c}{ Karakteristik } & Min & Max & Mean \pm SD \\
\hline Usia Ibu (tahun) & 22 & 41 & $30,66 \pm 5,88$ \\
\hline Paritas & 1 & 4 & $2,03 \pm 0,98$ \\
\hline $\begin{array}{l}\text { Usia Kehamilan } \\
\text { (minggu) }\end{array}$ & 37,2 & 41,5 & $39,50 \pm 1,13$ \\
\hline
\end{tabular}

Berdasarkan tabel 1 dapat dilihat bahwa dari 30 ibu bersalin dengan induksi didapatkan rerata usianya adalah $30,66 \pm 5,88$ tahun dengan rentan usia responden termuda adalah 22 tahun dan usia tertua adalah 41 tahun. Paritas rerata responden adalah 2,03 $\pm 0,98$ kali dengan rentan jumlah kehamilan paling rendah 1 kali dan paling tinggi 4 kali. Rerata usia kehamilan adalah 40,01 $\pm 1,19$ minggu dengan rentan usia kehamilan termuda 37 minggu 2 hari dan usia kehamilan tertua adalah 41 minggu 5 hari.

\section{Tabel 2. Nilai Bishop Ibu Kala 1 dengan} Persalinan Induksi

\begin{tabular}{ll}
\hline Nilai Bishop & $\mathbf{N}(\boldsymbol{\%})$ \\
\hline$<5$ & $19(63,3)$ \\
\hline$\geq 5$ & $11(36,7)$ \\
\hline Jumlah & $30(100)$ \\
\hline
\end{tabular}

Tabel 2 menunjukan bahwa sebagian besar ibu kala 1 dengan persalinan induksi memiliki nilai bishop kurang dari 5 yaitu sebanyak 19 orang $(63,3 \%)$. Hal ini serupa dengan penelitian yang dilakukan oleh Alash et al yang mendapatkan lebih dari $70 \%$ wanita 
yang telah mencapai usia kehamilan 42 minggu memiliki skor bishop $<5$.

Tabel 3. Terminasi Persalinan Ibu Kala 1 dengan Persalinan Induksi

\begin{tabular}{ll}
\hline Terminasi Persalinan & $\mathbf{N}(\boldsymbol{\%})$ \\
\hline Spontan & $17(56,6)$ \\
\hline SC & $12(40)$ \\
\hline Vakum Ekstraksi & $1(4,4)$ \\
\hline Jumlah & $30(100)$ \\
\hline
\end{tabular}

Jenis persalinan pada penelitian ini mayoritas secara spontan yaitu sebesar $56,6 \%$.

\section{PEMBAHASAN}

\section{Karakteristik Ibu Bersalin dengan Tindakan} induksi berdasarkan Usia Ibu

Hasil penelitian menunjukkan bahwa rentan usia ibu kala 1 pada persalinan dengan induksi antara $22-41$ tahun dengan rata-rata usia 30,66 tahun. Hal ini sesuai teori Mochtar (1998), Induksi persalinan dalam usia bahwa dalam usia yang paling baik usia produktif karena menimbulkan perubahan pada tonus otot polos dan pengaturan kerja hormon di saat proses induksi dengan baik, bila usia kurang dari 20 kurang baik melakukan suatu tindakan induksi sebab serviks yang dimatangkan kurang baik dalam usia tersebut begitu juga sebaliknya umur yang lebih dari 35 tahun serviks semakin kaku.

\section{Karakteristik Ibu Bersalin dengan tindakan induksi berdasarkan Usia Kehamilan}

Hasil penelitian didapatkan ibu kala 1 dengan persalinan induksi di RSUD K.R.M.T Wongsonegoro, Kota Semarang datang dengan usia kehamilan paling muda yaitu 37,2 minggu dan paling tua usia kehamilan 41,5 minggu. Karena makin tuanya kehamilan kejadian makin meningkat bahwa induksi melibatkan beberapa variabel, yang masing-masing bias mempengaruhi kepekaan rahim. Umumnya, rahim preterm kurang peka terhadap oksitosin dan bisa membutuhkan dosis yang lebih besar atau induksi serial. Jadi respons terhadap stimulant (perangsang) rahim nampaknya meningkat perlahan-lahan selama kehamilan sampai menjadi relative stabil setelah kehamilan 33 minggu. Dengan perkembangan ilmu pengetahuan dan teknologi obstetrik, kesempatan bagi induksi persalinan per vaginam semakin sempit, karena sebagian dilakukan langsung dengan seksio sesarea. Induksi persalinan pervaginam merupakan 'antara' menuju ke tindakan seksio sesarea. Itulah sebabnya bahwa setiap induksi persalinan dilakukan, sebaiknya disertai pertimbangan bahwa kegagalan persalinan per vaginam akan dilanjutkan dengan tindakan seksio sesarea yang harus dilakukan di Rumah Sakit yang dilengkapi dengan fasilitas operasi.

\section{Karakteristik Ibu Bersalin dengan Tindakan induksi berdasarkan Paritas}

Hasil penelitian menunjukkan bahwa paritas ibu kala 1 dengan persalinan induksi yang melahirkan di RSUD K.R.M.T Wongsonegoro, Kota Semarang antara $1-4$. Hal ini sesuai teori William (2001), Induksi persalinan dalam paritas biasanya yang paling baik yaitu multipara daripada primipara sebab kemungkinan keberhasilan induksi bisa diperkirakan dengan penilaian kematangan serviks dan konsisten dengan serviks yang belum matang. Oleh karena itu kematangan serviks sangat berpengaruh bila Dibandingkan dengan primigravida, induksi pada multipara akan lebih berhasil.

\section{Gambaran Nilai Bishop Pada Ibu Kala 1 dengan Persalinan Induksi}

Hasil penelitian mengatakan sebagian besar ibu kala 1 dengan persalinan induksi memiliki nilai bishop kurang dari 5 yaitu sebanyak 19 orang $(63,3 \%)$. Hal ini serupa dengan penelitian yang dilakukan oleh Alash et al yang mendapatkan lebih dari $70 \%$ wanita yang telah mencapai usia kehamilan 42 minggu memiliki skor bishop <5. Proses pematangan serviks dapat dipengaruhi hormon lain seperti estrogen yang dapat menstimulasi aktifitas degradasi yaitu degradasi dari kolagen serviks dan progesteron bersifat kebailkannya yaitu memblokade aktifitas tersebut. Sehingga tingginya kadar progesteron pada wanita ataupun kurangnya kadar estrogen seperti pada kelainan gen $x$-linked recessive defisiensi sulfatase plasenta, pematangan serviks menjadi terhambat untuk terjadi. 
Gambaran Terminasi Persalinan Pada Ibu Kala 1 dengan Persalinan Induksi

Di RSUD K.R.M.T Wongsonegoro, Kota Semarang sebagian besar ibu melahirkan secara spontan yaitu sebesar $56,6 \%$. Sisanya 43,4\% melahirkan dengan tindakan SC dan Vakum ekstrasi karena indikasi gagal induksi. Menurut teori, drip oksitosin akan lebih efektif menstimulasi kontraksi uterus apabila serviks telah matang. Pada pasien yang gagal induksi kemudian dilakukan persalinan SC dan Vakum ekstraksi dimungkinkan karena nilai shop yang $<5$.

\section{KESIMPULAN}

Berdasarkan hasil penelitian yang telah dilakukan pada 30 ibu bersalin kala 1 dengan induksi pada Ketuban Pecah Dini Di RSUD K.R.M.T Wongsonegoro, Kota Semarang maka dapat disimpulkan sebagai berikut :

1. Ibu bersalin kala 1 dengan induksi pada Ketuban Pecah Dini rata rata berusia $30,66 \pm 5,88$ tahun dengan rentan usia responden termuda adalah 22 tahun dan usia tertua adalah 41 tahun.

2. Ibu bersalin kala 1 dengan induksi pada Ketuban Pecah Dini rerata memiliki julah paritas adalah 2,03 $\pm 0,98$ kali dengan rentan jumlah kehamilan paling rendah 1 kali dan paling tinggi 4 kali.

3. Ibu bersalin kala 1 dengan induksi pada Ketuban Pecah Dini Rerata usia kehamilan adalah 40,01 $\pm 1,19$ minggu dengan rentan usia kehamilan termuda 37 minggu 2 hari dan usia kehamilan tertua adalah 41 minggu 5 hari.

4. Jumlah ibu bersalin kala 1 dengan induksi pada Ketuban Pecah Dini yang memiliki nilai bishop kurang dari 5 yaitu sebanyak 19 orang $(63,3 \%)$.

5. Jumlah ibu bersalin kala 1 dengan induksi pada Ketuban Pecah Dini sebagia besar cara terminasi persalinanya dengan spontan atau pervaginam yaitu sebesar $56,6 \%$.

\section{SARAN}

Penelitian ini merupakan penelitian untuk mencari data dasar tentang karakteristik ibu bersalin kala 1 dengan induksi pada Ketuban Pecah Dini sehingga diharapkan penelitian selanjutnya dapat meneliti tentang pengaruh atau hubungan karakteristik ibu, nilai bishop dan cara terminasi persalinan dengan keberhasilan induksi.

\section{DAFTAR PUSTAKA}

Arikunto, S. 2007. Prosedur Penelitian. Jakarta : Rineka Cipta.

Manuaba, Ida Bagus Gede. 2007. Pengantar Kuliah Obstetri. Edisi I. Jakarta: EGC

Notoatmodjo, S. 2003. Pendidikan dan Perilaku kesehatan. Jakarta : Rineka Cipta

Nursalam. 2007. Konsep dan Penerapan Metodelogi Penelitian Ilmu Keperawatan: Pedoman Skripsi Tesis dan Instrumen Penelitian. Jakarta: Salemba Medika

Sugiyono. 2010. Metode Penelitian Kuantitatif, Kualitatif dan $R \& D$. Bandung : Alfabeta

Mochtar R, 1998. Induksi pada persalinan, Sinopsis Obstetri jilid 2. Jakarta : EGC

Prawirohardjo S, 2002. Ilmu Kebidanan. Edisi Ketiga. Jakarta.: YBPSP.

Rayburn, William F. 2001. Obstetri \& Ginekologi. Jakarta : Widya Medi

Mozurkewich E CJ, Koepke E, Keeton K, King VJ. Indications for induction of labour: a best-evidence review. PubMed. 2009:62636.

Bomba-Opoń D, Drews K, Huras H, Laudański P, Paszkowski TP, Wielgoś M. Polish Gynecological Society recommendations for labor induction. Ginekologia Polska. 2017;88(4):224-34.

Organization WH. WHO recommendations for induction of labour: Geneva: World Health Organization; 2011.

Fraser DM, Cooper MA. Buku Ajar Bidan Myles, Edisi 14. Jakarta: EGC; 2009. 42860; 521-9 p.

Manuaba I, Manuaba C, Manuaba IF. Pengantar Kuliah Obstetri. Jakarta: EGC; 2007. 38-9; 90; 159-61; 210-5 p.

Christina A. Penfield DAW. Labor Induction Techniques: Which Is the Best? Obstetrics and Gynecology Clinics of North America. 2017; Volume 44, 2017(Issue 4):567-82.

Saifuddin AB. Buku Acuan Nasional Pelayanan Kesehatan Maternal Dan Neonatal. Jakarta: Yayasan Bina Pustaka Sarwono Prawirohardjo; 2010. 100-10; 218-20 p. 
Tenore JL. Methods for cervical ripening and induction of labor. American family physician. 2006;67(10):2123-8.

Gommers JS, Diederen M, Wilkinson C, Turnbull D, Mol BW. Risk of maternal, fetal and neonatal complications associated with the use of the transcervical balloon catheter in induction of labour: A systematic review. European Journal of Obstetrics and Gynecology and Reproductive Biology. 2017;218:73-84.

Ryan R, McCarthy F. Induction of labour. Obstetrics, Gynaecology \& Reproductive Medicine. 2016;26(10):304-10.

William A. Grobman JB, Yinglei Lai, Uma M. Reddy, Ronald J. Wapner, Michael W. Varner, John M. Thorp, Kenneth J. Leveno, Steve N. Caritis, Mona Prasad, Alan T.N. Tita, George Saade, Yoram Sorokin, Dwight J. Rouse, Sean C. Blackwell, Jorge E. Tolosa, . Defining failed induction of labor, In American Journal of Obstetrics and Gynecology. American Journal of Obstetrics and Gynecology 2017.

Grobman WA, Bailit J, Lai Y, Reddy UM, Wapner RJ, Varner MW, et al. Defining failed induction of labor. American Journal of Obstetrics and Gynecology. 2018;218(1):122.e1-.e8.f
Kui Li YW, Haiyan Li, Huixia Yang. A study of 579 pregnant women with premature rupture of membranes at term. International Journal of Gynecology \& Obstetrics 2011;112(1):45-7.

Güngördük K, Asicioglu O, Besimoglu B, Güngördük $\mathrm{OC}$, Yildirm $\mathrm{G}$, Ark $\mathrm{C}$, et al. Labor induction in term premature rupture of membranes: comparison between oxytocin and dinoprostone followed 6 hours later by oxytocin. American journal of obstetrics and gynecology. 2012;206(1):60. e1-. e8.

Lorthe E, Quere M, Kayem G. Prolonged latency after preterm premature rupture of membranes: an independent risk factor for neonatal sepsis? American Journal of Obstetrics \& Gynecology. 2017;216(1):8 